\title{
Moving Beyond Consultation And Into Action With A Client Project
}

Sara Ewing, Salisbury University, USA

Howard F. Dover, Salisbury University, USA

\begin{abstract}
Attempting to implement client-based projects within a single semester often overwhelms students and underwhelms the client and grading professor. In this paper, we share results from a two-year pilot project in which the components of a client project were split between several classes. We discuss the client project model as a valuable teaching method that allows students to implement and reflect on marketing strategies. We show that by dividing the project across several teams, the project becomes more manageable and valuable for students and professors. In comparison to other common projects, the client project presented here produced substantial and valuable outcomes for the non-profit client while providing students the unique experience of working in a multiple team structure. We indicate that this approach may be useful for select marketing classes.
\end{abstract}

Keywords: Experiential Learning Theory; Client Projects; Multi-Class Collaboration

\section{INTRODUCTION}

n recent years, there has been a trend in marketing education away from teacher-centered lectures toward student-centered learning (Johnson, Johnson and Smith, 1991; Razzouk, Seitz and Rizkallah, 2003; Wooldridge, 2006). In the most recent publication of its Eligibility Procedures and Standards for Business Accreditation, the Association to Advance Collegiate Schools of Business (AACSB) describes the need for "action-learning practices" stating that "the pedagogy and delivery mechanisms of higher education are changing rapidly" and that "faculty as a whole should encourage instructional innovation." (AACSB, 2010) Active and experiential learning strategies are well noted in marketing education with a variety of methods described. Some of the most widely used strategies include simulation, team learning, micro-business, case study, internship, live-case study, and client-based projects (Bovinet, 2000; Dyer and Shumann, 1993; Elam and Spotts, 2004; Hawes and Foley, 2006; Gremler, Hoffman, Keaveney and Wright, 2000; Laverie, 2006; Li, Greenberg, and Nicholls, 2007; Peterson and Albertso, 2006; Wooldrige, 2006). The outcomes of the strategies discussed are most often favorable, especially when analyzed from the student perspective. Karns (2005) finds that "marketing students tend to prefer active, applied, real-world pedagogies. Activities that were more applied and specific were seen as more effective in contributing to learning." Most notably, students prefer applied activities that involve the students in actual business problems.

\section{EXPERIENTIAL LEARNING THEORY}

Kolb has been influential in his development of experiential learning theory (ELT) and its roots in the learning styles inventory. He defines experiential learning as "the process whereby knowledge is created through the transformation of experience. Knowledge results from the combination of grasping and transforming experience (Kolb 1984, 41). Kolb continues to describe ELT, in more recent work, as an experience that requires the learner to decide which learning ability to use in any given situation (Kolb, 2005). The term 'active learning' stems from this theory in that this process requires the learner to engage in an activity and become an active participant in the learning process. ELT emphasizes the central role that experience plays in the learning process (Kolb, 2005). While many experiential learning strategies exist (as noted above), live-case studies and client projects have been noted as significant learning strategies in terms of positive student perception and benefits to students (Barnett, et al, 2007; Karns, 2005; Kennedy, et al, 2001; Lopez, 2005). 


\section{Live Cases v. Client Projects}

The pedagogical tool that requires students to interact with the management of an organization to gain access to inside information and to understand, analyze and provide a solution to a real problem has been termed differently. Goodell and Kraft (1991) described "applied client class projects" as an "experiential learning device in which students are required to conceptualize and solve actual business problems with the application of appropriate theories and technologies." Client projects actively engage students in a business problem, which requires them to use many procedures and techniques. "Live case study" has regularly been used to describe nearly the same method of teaching and learning as defined above (Elam, 2004). Camarero (et al, 2009) defines live cases as "an opportunity to integrate academic and work experiences in the creation of a consulting solution for a real problem." Both client projects and live case studies require students to become actively engaged in the learning process through an actual business problem. The benefits of such projects are clear. Students develop critical thinking and interpersonal skills, apply theory to practice, develop a deeper understanding of concepts and become invested in the learning (Lopez, 2005; Kennedy et al, 2001). Smith and Van Dorn (2004) argue that one of the defining factors of reality-based learning is the development of widely applicable, transferable skills.

For the purpose of this paper we define live cases as the experiential learning device that requires the learner to act as a business consultant and offer solutions to a real problem based on the current business situation. Client projects are defined as the experiential learning device that requires the learner to provide service to a business by iteratively implementing a solution to a given business situation. Client projects are unique because they do not have pre-defined procedures and problems such as in simulations and cases (Goodell and Kraft 1991).

\section{THE PROBLEM}

In accordance with those standards, we have been looking for ways to use client projects to engage students in hands-on learning experiences. To this end, two professors introduced client projects as the major project in both promotions and sales classes. These client projects allowed students to work with a local non-profit organization to host a fundraising event. However, initial attempts produced unsatisfactory outcomes. Often the scope of client projects exceeded the capacity of undergraduate students, due to the time constraints imposed by academic semesters. Those challenges led to poorly executed events and made it difficult for the professors involved to evaluate performance and learning outcomes in both promotions and sales classes. Often student groups would focus on good event planning, promotions, or sales, but rarely were teams able to accomplish all three.

Despite the difficulties that client projects present, there is value in the client project model. Client projects provide invaluable assessment and reflection opportunities because of the real challenges students face when dealing with a live event for a client. In addition, professors are able to facilitate deeper learning when students are able to honestly evaluate outcomes from real events. Benefits also exist from the client perspective. Participating non-profit organizations are poised to gain significant value, through increased awareness and possible fund-raising efforts from the client projects that occur. These events provide valuable service to non-profits, invaluable experiences to students, as well as constructive outreach opportunities and goodwill for the Business School and University.

Thus, a pilot project has been explored over two years in search of a better method to implement client projects in both the promotions and sales classes. Professors from both classes jointly developed a replicable event, which required a collaborative effort and strategies from both promotions and sales teams to accomplish a successful event.

\section{RELATION TO MARKETING CURRICULUM}

The goal of the project is to facilitate experiential learning, which allows students to explore marketing theory via live application opportunities. In the promotions class, the client project requires students to plan, execute, and promote an actual event. Since the event is held prior to the end of the semester, students are able to honestly evaluate the effectiveness of their promotional elements, including press releases, ad copy, and public service announcements. In the sales class, experiential opportunities are essential to motivate students to value the various steps within the sales process. Using this client project, sales students experience the value of concepts such 
as targeting, prospecting, and handling objections first hand. Sales students are able to not only develop, but also execute sales dialogues and communication strategies. The second year addition of a virtual event through an emarketing course allowed e-marketing students to immediately assess the effectiveness of their online promotional strategy, including e-mail campaigns, social networking strategies, and web site design strategies.

\section{THE INNOVATION}

The client project, called Jail \& Bail, is a fundraising event in support of a local non-profit organization. The event requires individuals from the community to volunteer on a set date and time to "jail" themselves and solicit donations to make "bail". The event is held on campus during the evening. "Jail birds" have the opportunity to line up donations ahead of the event and make phone calls during the evening to raise money to a specified goal.

One goal of the project is to allow students to follow the event from consultation in the beginning to donations collection in the end. An important objective is that students will evaluate the success of their strategies and adaptations by measuring their effectiveness against previously proposed goals. Other objectives are focused to allow students to gain experience in a collaborative and dynamic environment. Table 1 is provided to show the project objectives for the students and goals for the professor.

Students form teams from the promotions and sales courses, and in the most recent year an e-marketing course, that develop strategies to plan, organize and implement the entire event. The structure of the project is similar to an IMC in which the campaign is developed from multiple angles simultaneously. The project's varied activities and responsibilities are distributed to the various teams from each course to make the project more manageable. The tasks performed by each team are directly related to course objectives for the respective classes.

Table 1: Jail \& Bail Multi Course Project Objectives

\begin{tabular}{|l|l|}
\hline \multicolumn{1}{|c|}{ Student Objectives } & \multicolumn{1}{c|}{ Instructor Goals } \\
\hline - collaborate in a multi-team, cross-course environment which & $\begin{array}{l}\text { convey the concept of the dynamic marketplace by } \\
\text { allowing students to work in a live environment and } \\
\text { requires definition of the scope of work in order to }\end{array}$ \\
$\begin{array}{l}\text { implement and evaluate their promotional strategies within a } \\
\text { single semester }\end{array}$ & $\begin{array}{l}\text { one semester course } \\
\text { add value to a client project by allowing students to } \\
\text { work toward identified client goals }\end{array}$ \\
$\begin{array}{l}\text { - develop action plans across teams which will be implemented } \\
\text { on behalf of an actual client }\end{array}$ & $\begin{array}{l}\text { implement a full promotional cycle within one } \\
\text { semester by dividing labor among courses }\end{array}$ \\
$\begin{array}{l}\text { process to meet identified goals within a specified timeline } \\
\text { evaluate the success of strategies and adaptations by } \\
\text { measuring their effectiveness against previously proposed } \\
\text { goals }\end{array}$ & \\
\hline
\end{tabular}

The scope of the project is large enough that the promotions, sales, and e-marketing teams can carry out different phases of the project without unnecessary overlap and their activities allow them to practice theories discussed in the different marketing courses. Table 2 is provided to describe required activities for different courses.

Students from all courses require significant support from instructors in order to be successful in bringing the project to completion. The promotions students received project guidelines via the course syllabus and traditional course materials and instruction. In the second year, these students made use of a binder compiled from the previous year, which contained feedback from the groups and online discussion boards. The binder helped promotions teams in the second year to assess previous strategies and build upon tried methods. The instructor provided a guideline of activities to facilitate the development of the campaign. E-marketing students were given access to the client's Webmaster in addition to traditional course materials. 
Table 2: Required Activities by Course

\begin{tabular}{|l|l|}
\hline Promotions & - Secure an appropriate location and date \\
& - Pre-event promotions and public relations \\
- Organize event layout and develop activities \\
- Coordinate media coverage \\
- Develop marketing materials used by Jail \& Bail participants \\
- Develop sales materials used by sales staff to recruit jail birds such as the initial script, \\
& - brochures, information flyers, e-mail communications \\
\hline Sales & $\begin{array}{l}\text { - Reach a two-tiered quota consisting of a set number of secured jail birds and donations of } \\
\text { - \$1,000 per jail bird }\end{array}$ \\
& $\begin{array}{l}\text { - Covelop lists of potential jail birds } \\
\text { - Maintain relationships with jail birds until the event is complete }\end{array}$ \\
& - Confirm the jail birds' participation in the event \\
\hline E-marketing & $\begin{array}{l}\text { - develop e-mail campaign } \\
\text { - design Facebook page, build fan list, and run ads }\end{array}$ \\
\hline
\end{tabular}

Sales students were guided through the planning stages of the sales process via course management software. These sales students receive instruction via online class modules and a written project description accessible in the course management system. Additionally, students submit prospect lists online and engage in dialogue through the discussion board. In the second year, sales teams received a list of participants from the previous year before they began developing prospects.

The project is most appropriate for students of undergraduate level courses who have basic marketing foundations. A number of desired outcomes are achieved during the project. Through participation, students develop (1) an appreciation for the processes and the value of their individual elements; (2) the understanding that marketing campaigns are adaptive processes that require full cycle decision making to be effective; (3) the experience of interteam dynamics and understanding of how to accomplish objectives across multi-dimensional teams; (4) a realistic understanding of how marketing strategy adds value to an organization. By allowing students in different courses to collaborate, each team is able to better focus on their respective course responsibilities.

Student teams worked toward their goals for approximately two months. Teams from different courses held meetings periodically to discuss the project and regularly shared information online to move the project forward. Teamwork is of the essence in achieving results. Teams of three to five students are formed from courses with an average enrollment of 25 students.

Students in the promotions, sales, and e-marketing courses are evaluated at the end of the project through a reporting process and self-evaluation. The client project is unique because it allows students to evaluate the effectiveness of their implemented strategies. Therefore, the personal reflection is a major component of the final evaluation. Students are expected to report on the promotion and sales strategies they developed in the consultation phase as well as how effective those strategies were upon implementation. The real value is found in the latter reflection. In our experience, client projects provide a unique teaching method that allows students to assess how effective their strategies have been. Simulations may be the next best method for allowing an implementation phase; however simulations exist only in a controlled environment. Therefore, the use of client projects can be a powerful tool to teach students that "the best laid plans often go awry."

One of the major outcomes of the project is that students developed an appreciation for the challenges of actually executing their planned promotions and sales strategies. For example, the sales teams quickly realized that modifications in their prospecting strategy were required. From a sales perspective, students had real examples of how to handle objections in actual situations. These results are rarely achieved through other types of projects. 


\section{RESULTS}

The innovation of developing multi-course teams to hold an event addresses the problem of students not having sufficient time to accomplish viable and valuable client projects. While the project is still demanding on students, by distributing the various tasks, as outlined in Table 2, students were able to focus their efforts and provide substantially greater outcomes than previous client projects. Prior to this project, most events would be fortunate to raise one thousand dollars for a local non-profit. However, the result of the Jail \& Bail event showed a marked improvement in community participation and funds raised. In the first year, 18 jail birds were recruited by students in two sales course sections (9 teams) and six 'jail birds' were recruited by the non-profit organization. During the live event, $\$ 3,800$ of the $\$ 7,000$ pledged could be credited to the student recruited jail birds. However, only $60 \%$ of the pledge amounts were eventually collected, providing a final total of $\$ 4,200$. In the second year, 22 jail birds were recruited by a single sales team of three students. A total of $\$ 8,000$ was collected in donations, of which $\$ 4,200$ was collected through the website before the live event. The addition of the virtual event was a substantial addition to the second year's success.

Figure 1: Required Activities by Course

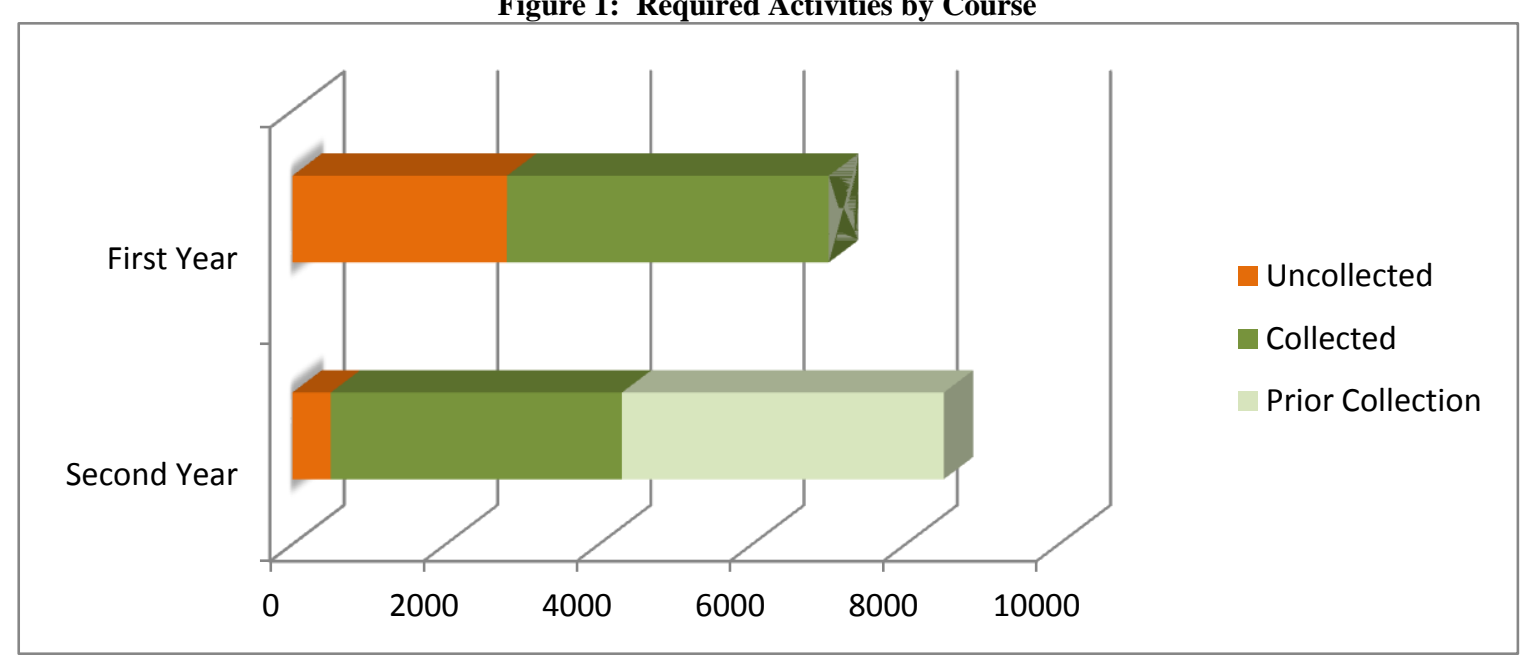
responses:

Through the reflection process, students commented on the value of the project with the following

This project was one of the best compared to other projects I have previously participated in. Being part of this project, I discovered how promotions and sales departments influence and depend on one another. I was able to apply what I learn in class to an event that raised money for a worthy cause. This project was also a great learning experience being part of a team in a cross-course environment.

This project was unique in that the assignment was not just to work within your group to complete the project. The Jail and Bail depended on the coordination and cooperation of volunteers placing themselves in "jail", advertisement and sponsorship from local radio stations and other media outlets, and working with the University as a venue and SU Foundations for approval of donors and participants. If I had participated in a different project, I know I would not have accomplished or learned as much as I did with this project.

Working in a multi-team, cross-course environment, you learn more than what you would have reading about it in a textbook. It's a real hands-on-experience of how events are executed, what problems and conflicts may arise, and how to tackle and accomplish them. The project encompasses all marketing aspects and I'm proud to have been part of it." 
I enjoyed working for a real client because it gave me hands on experience in a safe environment. I have never had such an opportunity before.

...this project really mattered. That placed a sense of importance on the project that went far beyond earning a grade. If felt that I had an obligation to the non-profit to do well on their behalf.

This project gave you a hands-on experience. I actually had to call complete strangers and convince them to participate. I dealt with rejection and cold calling. By actually applying the info I had learned in class, I was able to really understand it.

The most valuable parts of the project were being able to observe what did and did not work for an actual event as well as feeling successful about the outcome of the project.

\section{LIMITATIONS}

Undertaking a client project can be a challenge for some professors or at certain universities. Indeed, this type of project will work best at teaching universities where class sizes are small. We recognize that it is logistically difficult to involve a large number of students in a project of this scale. The project can be offered as an optional extra-credit assignment, which will help to limit the number of students participating and ensure team members are committed to success.

Professors considering a client project should be aware that the project requires a great deal of planning in the first year. However if the project is to continue year over year, the foundation will be in place after the first year. The process will get easier on the professor each time the project is done. Additionally, some traditional class time is sacrificed to explain and coach the project. It is helpful to use course management software to deal with project issues outside of regular class time.

Inter-team processes can be a new concept to students. To address team dynamics, students were coached on how to negotiate responsibilities and taught the value of defining and limiting their scope. While these coaching sessions occurred outside class, the lessons learned from these sessions were worth the effort. This is actually one of the major benefits of this innovation, as it provides an opportunity for students to experience these challenges and the effectiveness of implementing different strategies for handling these types of issues.

\section{ADAPTABILITY OF THE INNOVATION}

The model presented allows undergraduate students to plan, implement, and evaluate a client project with a reasonable scope. The current model could be expanded to include all promotions teams matched to sales teams and e-marketing teams. Professors in each course will need to develop a common set of standards across courses to improve consistency and collaboration. As evidenced by the expansion of the project in the second year to three marketing classes, the concept can be employed in various types of classes.

This approach seems appropriate for upper division, undergraduate marketing classes but not in a capstone course. It can serve as a valuable method by which students can gain experience on the dynamics of cross-functional teams. Implementation in a graduate program would be logistically challenging because the various functions of marketing are not commonly taught concurrently in a graduate program.

\section{CONCLUSION}

Client projects are an experiential learning device that can be used to address the needs of students in multiple courses. Jail \& Bail is an example of a client project. The project allows students to apply theory to realworld practice and exposes them to the challenges of working within constraints. The nature of the event requires students to not only plan, but also implement their promotion and sales strategies. The existence of the implementation phase provides students the opportunity to evaluate the effectiveness of their strategic decisions. In addition, the non-profit organization benefits from the services provided and the University and Business School 
develop good will within the community. We feel that client projects are a valuable experiential activity that produces beneficial outcomes for students, professors, and non-profit organizations.

\section{AUTHOR INFORMATION}

Sara Ewing is a graduate of the Salisbury University M.B.A. program. She is a business owner and a marketing instructor. E-mail: sara.ewing4@gmail.com

Dr. Howard F. Dover is an Assistant Marketing Professor at Salisbury University's Perdue School of Business. His primary areas of research are the intersection of sales and marketing with a specific focus on customer lifetime value. He values experiential learning techniques in the classroom and serves as a faculty sales and marketing coach for sales and marketing competitions at the Perdue School of Business. E-mail: hfddover@salisbury.edu. Corresponding author.

\section{REFERENCES}

1. AACSB International (2010, January 31, Revised). Eligibility Procedures and Standards for Business Accreditation. Retrieved April 11, 2010, from http://www.aacsb.edu/accreditation/standards.asp.

2. Bovinet, J. W. (2000), "Interdisciplinary Teaching Combined with Computer-Based Simulation: A Descriptive Model," Marketing Education Review, 10 (3), 53-62.

3. Dyer, B. and D. W. Shumann (1993), "Partnering Knowledge and Experience: The Business Classroom as a Laboratory," Marketing Education Review, 3 (2), 32-39.

4. Elam, E. L. R. and H. E. Spotts (2004), "Achieving Marketing Curriculum Integration: A Live Case Study Approach," Journal of Marketing Education, 26 (1), 50-65.

5. $\quad$ Gremler, D. D., K. D. Hoffman, S. M. Keaveney, and L. K. Wright (2000), "Experiential Learning Exercises in Services Marketing Courses," Journal of Marketing Education, 22 (April), 35-44.

6. Hawes, J. M., and L. M. Foley (2006), "Building Skills With Professional Activity Reports," Marketing Education Review, 16 (1), 35-40.

7. Johnson, David W., Roger T. Johnson, \& Karl A. Smith (1991), "Cooperative Learning: Increasing College Faculty Instructional Productivity,” ASHE-ERIC Higher Education Report No. 4. Washington, DC: The George Washington University, School of Education and Human Development.

8. Karns, G. L. (2005), "An Update of Marketing Student Perceptions of Learning Activities: Structure, Preferences, and Effectiveness," Journal of Marketing Education, 27 (2), 163-71.

9. Kennedy, E. J., L. Lawton and E. Walker (2001), “The Case for Using Live Cases: Shifting the Paradigm in Marketing Education," Journal of Marketing Education, 23 (2), 145-51.

10. Laverie, D. A. (2006), "In-Class Active Cooperative Learning: A Way to Build Knowledge and Skills in Marketing Courses," Marketing Education Review, 16 (2), 172-88.

11. Li, T., B. A. Greenberg and J.A.F. Nicholls (2007), "Teaching Experiential Learning: Adoption of an Innovative Course in an MBA Marketing Curriculum," Journal of Marketing Education, 29 (1), 25-33.

12. Lopez, T. B. and R.G. Lee (2005), "Five Principles for Workable Client-Based Projects: Lessons from the Trenches," Journal of Marketing Education, 27 (2), 172-88.

13. Peterson, R. M. and D.E. Albertson (2006), "Running a Micro Business in Marketing Class: Experiential Learning Right Out of the Gate," Marketing Education Review, 16 (1), 105-09.

14. Razzouk, N.Y., Seitz, V. and Rizkallah, E. (2003), "Learning By Doing: Using Experiential Projects in the Undergraduate Marketing Strategy Course," Marketing Education Review, 13 (2), 35-41.

15. Smith, L. W. and D.C. Van Doren (2004), "The Reality-Based Learning Method: A Simple Method for Keeping Teaching Activities Relevant and Effective," Journal of Marketing Education, 26 (1), 66-74.

16. Wooldridge, B. R. (2006), "The Power of Perception An Active/Experiential Learning Exercise for Principles of Marketing," Marketing Education Review, 16 (2), 5-8. 
NOTES 